\title{
$\mathrm{CA}^{\mathrm{cos}}$

\section{Squatter Regionalism: Postwar Fiction, Geography, and the Program Era}

\author{
Nicholas M. Kelly, Nicole White, and Loren Glass
}

Nicholas M. Kelly, New Mexico Tech

Nikki White, University of lowa

Loren Glass, University of lowa

Peer-Reviewer: Mark McGurl

Data Repository: 10.7910/DVN/CQURIW

\begin{abstract}
A B S T R A C T
In this article we use computational methods to establish that the Program Era has altered the traditional understanding that a regionalist writer writes about the region in which they grew up. Using the Iowa Writers' Workshop as an example, we prove that many writers now write about the region to which they moved to study and/or teach creative writing. Using a database of demographic information about faculty and students alongside computational analysis of place names in a curated corpus of work produced by prominent Iowa-affiliated writers, we map authorial career itineraries onto the geographic locations referenced in their fiction, visualizing the ways in which the relationship between writer and place has been inflected by the Midwestern location of the Workshop. We found that Iowa references are significantly higher than in a comparable corpus of postwar literature. They are also significantly higher in percentage terms than Iowa's population as a proportion of the US population. Finally, we found that the works in our corpus most centrally focused on Iowa are, overwhelmingly, not authored by Iowa natives. Instead, we have identified a cohort of squatter regionalists, authors whose writings prominently feature the state in which they received their MFA, found faculty employment, or (frequently) both. This trend, we believe, may also be evident in works by authors from other MFA programs, which would confirm our larger hypothesis that the professional itineraries mandated by the Program Era have influenced the regional settings of postwar

American

fiction.
\end{abstract}

The last chapter of Tom Lutz's landmark study Cosmopolitan Vistas: American Regionalism and Literary Value (2004) is ambitiously titled "The New New Regionalism and the Future of Literature." In it, Lutz reminds us that while conventional literary history confines classic regionalism to the turn of the twentieth century, a "large number of recent writers are also closely associated with the locales that are featured in their fiction and where they (usually) have a home." Lutz lists some of these writers, and then designates Chris Offutt's first short story collection, Kentucky Straight (1992), as an example of "classic literary regionalism."1 What Lutz neglects to mention is that Kentucky Straight began as an MFA thesis at the University of Iowa Writers' Workshop. While Offutt ended up writing about (and ultimately returning to) his home state, many of his colleagues at Iowa would choose to live in and write about their adopted state and region. Marilynne Robinson, Jane 
Smiley, W.P. Kinsella, and John Irving are just a few examples of writers not from Iowa who nevertheless set much of their fiction in this hitherto neglected state.

What constitutes or enables a "close association" with a place for an American writer? For traditional regionalism, it almost invariably meant that the author was born and grew up in the region featured in their fiction. And while Lutz concedes that recent regionalist writers may have more attenuated relations with the locales they write about, he nowhere mentions that many of the figures he lists-including Flannery O'Connor, Wallace Stegner, Ken Kesey, Wendell Berry, and Mary Swander-forged their regional sensibilities in association with their careers as students and teachers of creative writing. Is it possible that the Program Era has altered the traditional relation between writer and region, creating a new genre that could be called "squatter regionalism"? How might we use computational methods to prove the existence of such a genre?

For the last few years the Program Era Project (PEP), a collaborative initiative supported by the University of Iowa's Digital Scholarship and Publishing Studio (DSPS), has been gathering demographic information about Iowa-affiliated writers alongside textual metrics of their work. From a variety of sources both internal and external to the University, we have built a database of graduation dates; thesis titles, genres and advisors; and hometowns (and we're working on publishers, agents, prizes, and employment history). With the invaluable assistance of a data capsule provided through an Advanced Collaborative Support (ACS) Award from the HathiTrust Research Center (HTRC), we have also curated an expansive corpus of work produced by approximately 300 University of Iowa-affiliated writers. Together, this data enables us to map the career itineraries of these writers onto the geographic locations referenced in their fiction, visualizing the ways in which the relationship between writer and place has been inflected by the Midwestern location of the Iowa Writers' Workshop (IWW).

Our findings, on the whole, support our hypothesis about the existence of a distinct phenomenon we're calling squatter regionalism, though we will need further research to confirm its scale, scope, and significance. Using a custom-built text analysis tool, we have tracked location references in our corpus, determining which states are most frequently mentioned. We found that, while New York and, to a lesser extent, California predominate, Iowa references are significantly higher than in a comparable corpus of postwar literature collected through the TxtGeo project. They are also significantly higher in percentage terms than Iowa's population as a 
proportion of the US population. Most telling, we found that the works in our corpus most centrally focused on Iowa are, overwhelmingly, not authored by Iowa natives. Instead, we have identified a cohort of squatter regionalists, authors whose writings prominently feature the state in which they received their MFA, found faculty employment, or (frequently) both. This trend, we believe, may also be evident in works by authors from other MFA programs, which would confirm our larger hypothesis that the professional itineraries mandated by the Program Era have influenced the regional settings of postwar American fiction.

\section{Background, Methods, Corpus}

To assess regional representation in our corpus, we built a text analysis tool that counts state-related toponyms, including state names, state capitals, the fifty most populous cities in the U.S., and the four most populous cities in each state. ${ }^{2}$ As previous scholarship documents, disambiguating terms that can refer to multiple places (Washington State or Washington, DC) or even multiple things (George Washington, University of Washington, The Washington Companies) poses a significant challenge for toponym tracking. Different studies have taken varying approaches to address this challenge. For his study of location representation in Civil War-Era American Fiction, Matthew Wilkens used named entity recognition to acquire his initial collection of place names. He then evaluated these extracted location references manually based on the context in which they appeared, excluding false positives or unclear references. ${ }^{3}$ For their study of geospatial semantics in the Scottish Poet Ossian, Eric Gidal and Michael Gavin ${ }^{4}$ used a technique developed by David A. Smith and Gregory Crane for the Perseus Project. This complex method involves mathematically representing known place references on a contextual grid of values and then connecting an ambiguous toponym to a place by assessing its location on this grid. ${ }^{5}$

We use context to disambiguate place references in a way that we hope will be more transparent and comprehensible to students and scholars less familiar with computational analysis. Our tool works by first counting unambiguous place references, then using that information to assign the ambiguous place references to states. For instance, the tool will count unambiguous mentions of places in Washington State, Washington, D.C., or false positive instances of Washington used as a last name. Based on the representation of each unambiguous category (city, state, name), the tool then proportionally assigns ambiguous instances of just 
"Washington" to the appropriate category. ${ }^{6}$ Our aim with this disambiguation process is to employ a simple, transparent, and easy-to-understand heuristic that can account for the semantic ambiguities of place names.

Because regionalism is primarily used to categorize fiction, we decided to limit our corpus to this genre. We then narrowed it down further to works that feature at least 10 location references. Finally, the first and last five pages of all texts were removed to eliminate place mentions found in publication or biographical information. These criteria left us with a corpus of 500 works of fiction by approximately 150 authors.

\section{Mapping Corpus Data: Regionalist Test Cases}

Despite Wilkens's legitimate challenge to regionalism as a literary historical category, the term continues to be associated with the period of its emergence in the late-nineteenth century, when it was canonized as a mode of literary realism. Wilkens's significant findings complicate without undermining this traditional periodization. The regionalist writer during this era was invariably from the region they wrote about. A liminal figure, the classic regionalist straddled the distance between the peripheral location where they were raised and the metropole where they inevitably migrated to pursue a literary career.

From a selection of classical regionalist texts that exhibit this traditional relationship between writer and place, we use our tool to establish a baseline for comparison and map the development of regionalist writing over the last century. For each author, we provide a pair of choropleth map visualizations, each based on a different method of measuring the location references in the author's corpus. In the first method, we take each text in an author's corpus separately and determine what percentage of the total location references each state represents. We then find the mean of each state's percentage across texts, allowing us to see, on average, what percentage of total place references is made up by each state. This method, we believe, enables us to visualize location references with each text on an equal footing. Longer works (or works with more total location references) can't outweigh shorter works (or works that are less location dense). For our second method, we take the author's entire corpus and find what percentage of total state references each individual state represents. With this approach, we can register how consistently an author has mentioned a state or its locations across the entire body of writing available. An advantage of this method is that instances where a single text (or a small number of 
texts) have an extremely high percentage of references will not skew the overall measurement. This is particularly useful if these high percentages come from texts that have a lower overall number of location references. In most of the following examples, the results of each method differ little. Together, these methods measure both how often a state features prominently within each text in a corpus and how often a state appears throughout the entire corpus.
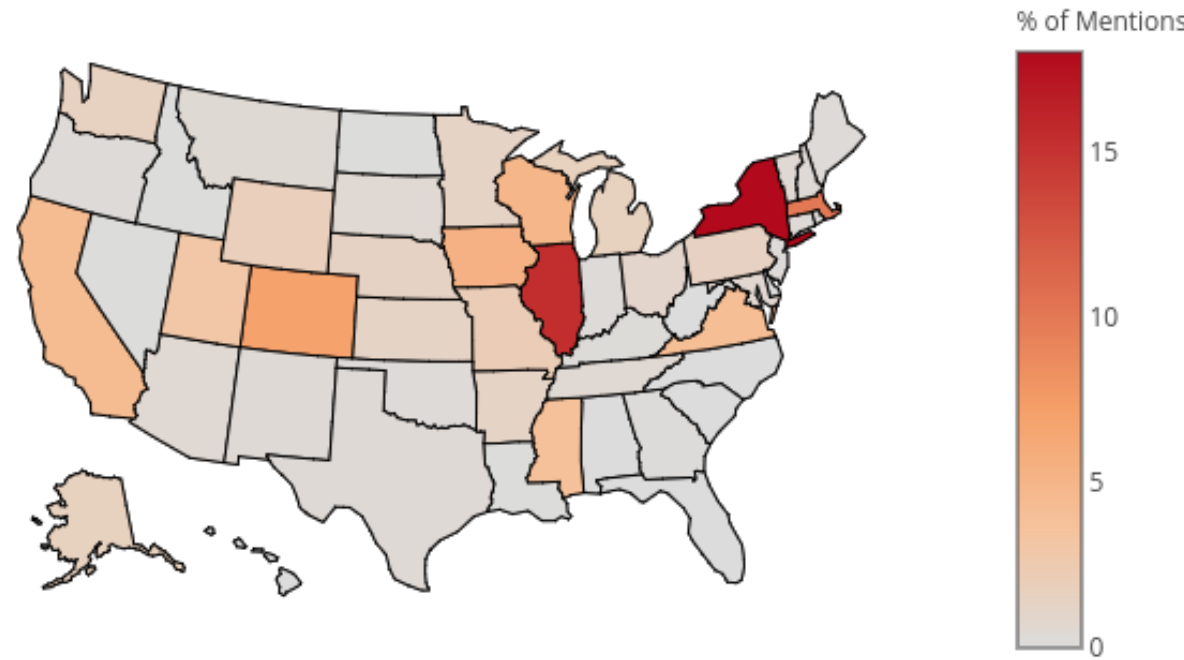


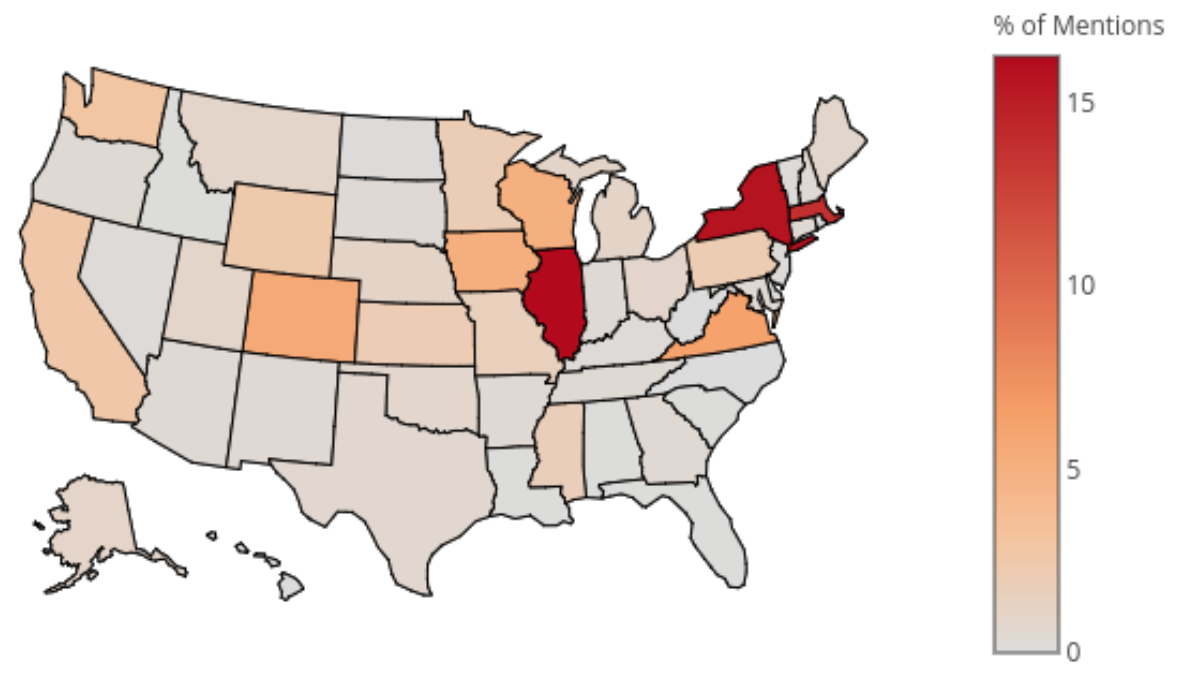

Figure 1. Average, Total Mentions by State, Hamlin Garland (1860-1940)

Born in Wisconsin. Raised in the Midwest. ${ }^{7}$

We begin with Hamlin Garland, whose geographical trajectory and career arc can be considered representative of classic regionalist writers more generally. Born on a farm in Wisconsin, Garland was an avid reader and an ambitious writer, determined to escape from his humble origins and make a literary name for himself on the East Coast. He moved to Boston as a young man and promptly caught the attention of William Dean Howells, editor of The Atlantic Monthly and arbiter of literary realism in the United States at the turn of the twentieth century. Garland's initial success came with the publication of his collection of semi-autobiographical short stories, Main-Traveled Roads, which focused on what he termed the "Middle Border," the agricultural region that had been the West but was becoming what we now call the Midwest. Garland would continue to mine this region for literary gold over the course of his career, achieving particular recognition for his autobiography, A Son of the Middle Border. Like most regionalism of this era, Garland's work is defined 
by its author's simultaneous origins in and departure from the location upon which he focuses. This personal distance maps onto the geopolitics of the literary world and publishing industry of the time, which was based on the East Coast, a region that Garland wrote about later in his career after he had achieved recognition as a regionalist, accounting for the prominence of New York and Massachusetts on our maps.
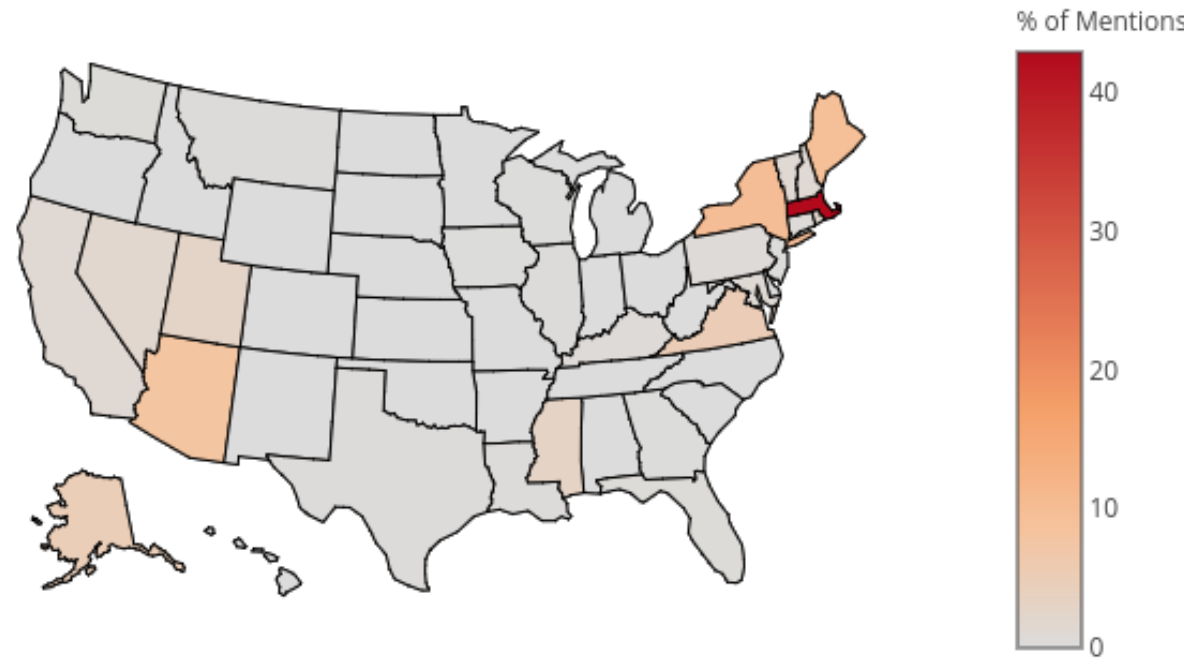

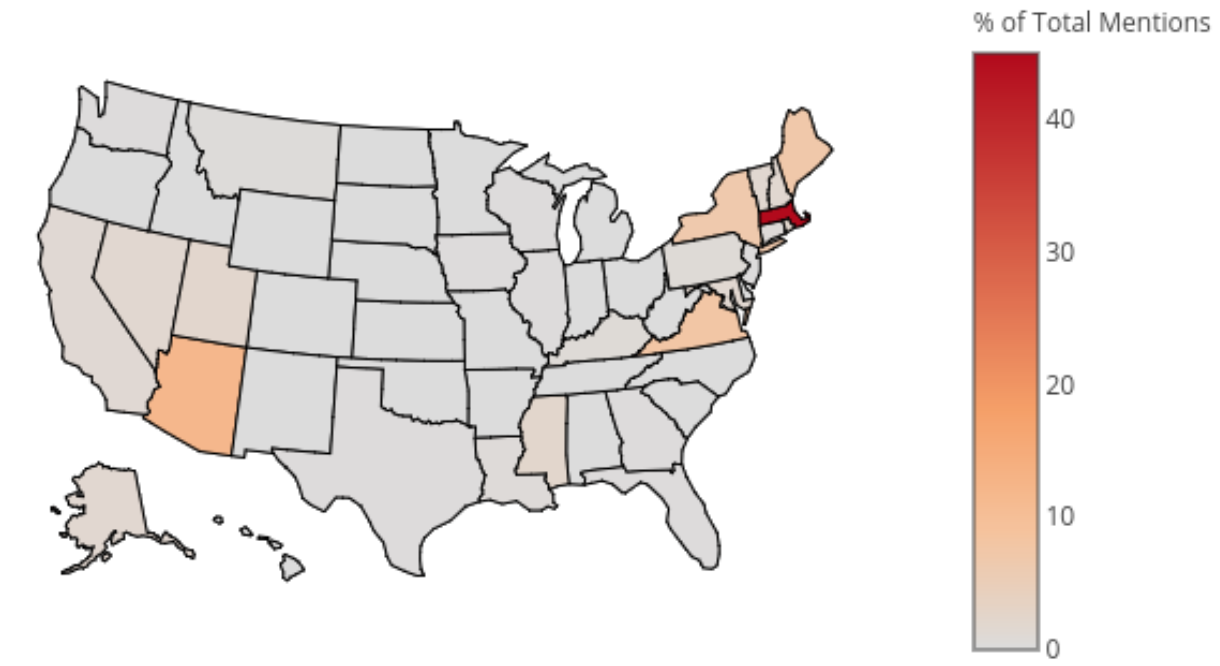

Figure 2. Average, Total Mentions by State, Sarah Orne Jewett (1849-1909).

Born in Maine. Lived entire life in New England ${ }^{8}$

We now turn to Sarah Orne Jewett, a regionalist writer who never left New England, the region where she was born and about which she wrote. If Garland wrote about a region that was coming to prominence as an agricultural (if not cultural) powerhouse, Jewett wrote about a region that was passing away, as the shipping industry based in New England began to fade and populations dwindled. Jewett's work is thus doubly nostalgic, marking a region that was not only lost to her but also vanishing from the modern socio economic order. Her family had lived in New England for generations, so she was documenting a culture she knew well. Based in the seaport town of South Berwick, Maine, Jewett was close to Boston, both geographically and professionally, where like Garland, she received crucial encouragement and patronage from William Dean Howells. Jewett's regional affiliations were more proximate than Garland's, but the same pattern of nostalgia and loss dominates her fiction. 
With these test visualizations of classic regionalism and the ones to follow, our tool essentially tells us what we already know. This is a good thing, confirming that we can reliably use it to explore regional trends and patterns in more recent texts. Moreover, we can later use this data to pull and examine macro level trends in regional representation, allowing us to explore the research questions raised by this project at a larger scale. To do this, we first need to briefly consider the period which intervenes between classical and squatter regionalism.

Literary modernism in the United States explicitly disavowed the representational aspirations of regionalism and established its own cosmopolitan credentials over and against the seemingly parochial concerns of what was dismissively called "local color" writing. Indeed, many American modernists abandoned the United States altogether, emigrating to Paris to join the expatriate bohemian communities of interwar Europe, where liquor was legal and the dollar was strong. Many of them left the United States imaginatively as well, choosing to write about Americans abroad. The author who stood out as the foundational exception to this rule was William Faulkner, whose native modernism established the South as America's region par excellence. Faulkner's resistance to the North's modernity would come to define the emergence of America's literary identity as such under the powerful academic auspices of the New Critics, Southerners all. 


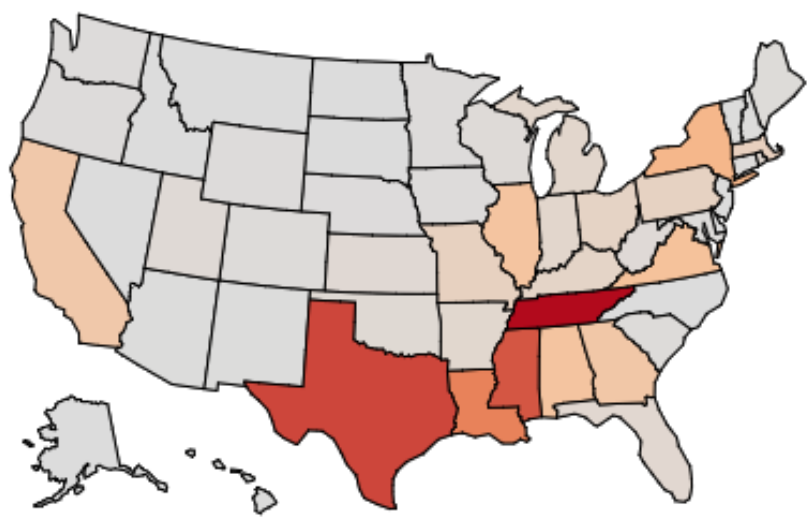

$\%$ of Total Mentions

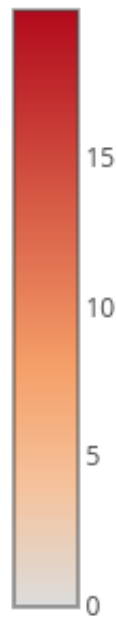



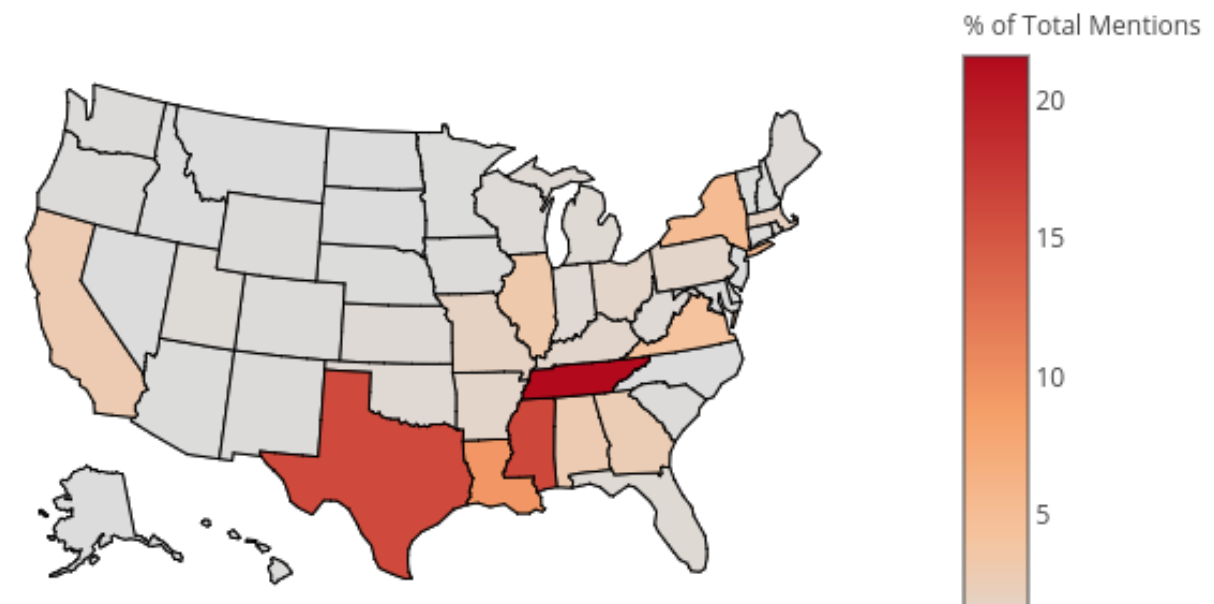

Figure 3. Average, Total Mentions by State, William Faulkner (1897-1962).

Born and raised in Mississippi. ${ }^{9}$ 
William Faulkner, Avg. \% of State Mentions (Yoknapatawpha, Jefferson Included)

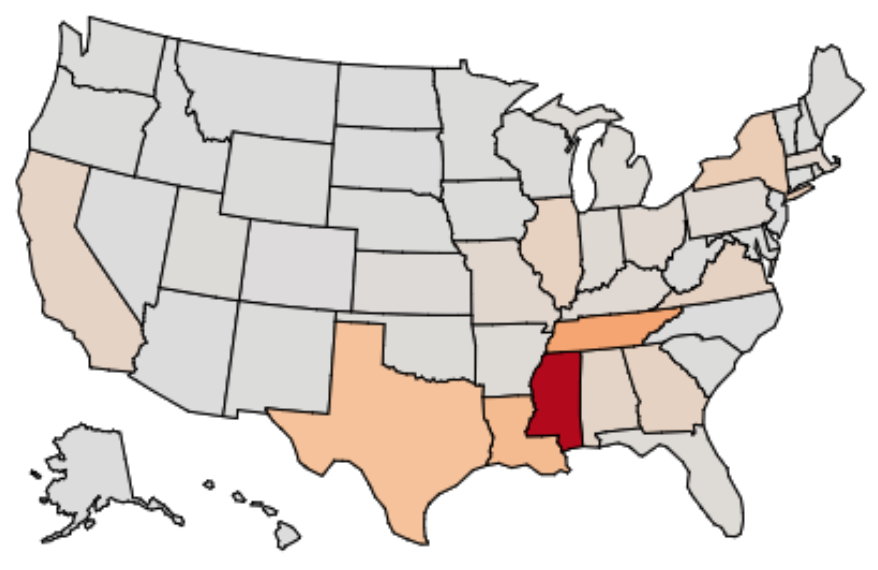

$\%$ of Mentions

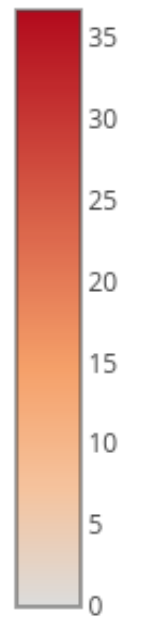




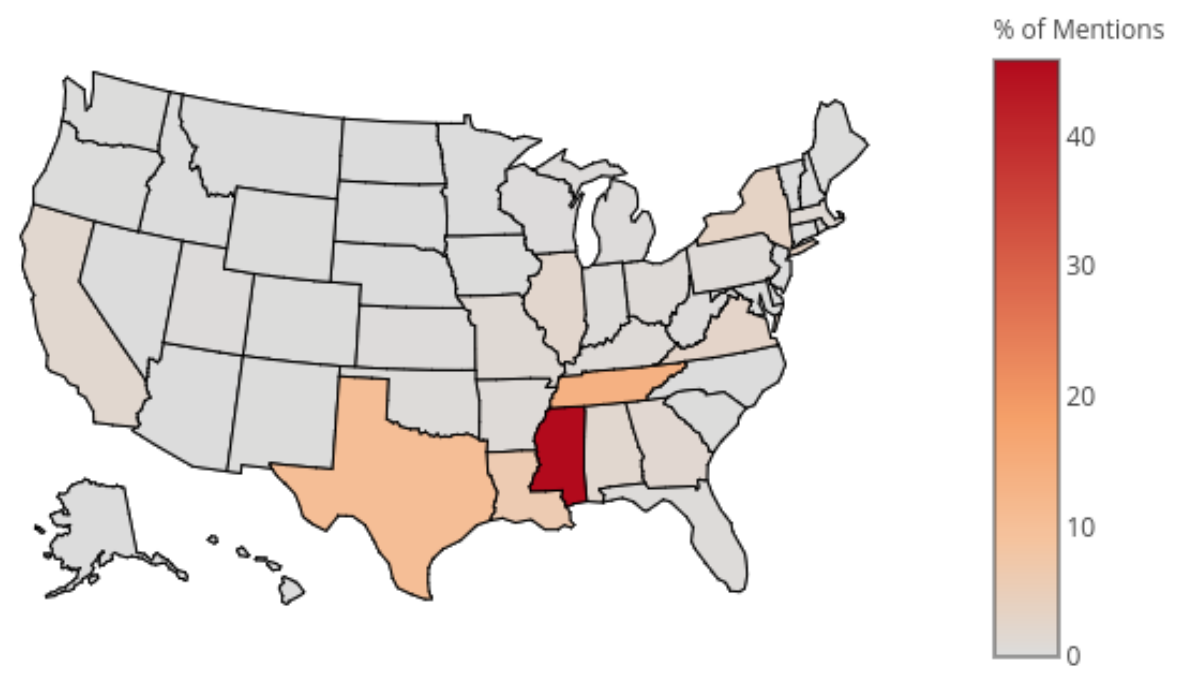

Figure 4. Average, Total Mentions by State, William Faulkner (1897-1962).

(Jefferson and Yoknapatawpha included)

William Faulkner famously situated his most significant works of fiction in the South generally and in Mississippi specifically, and this regional concentration is visibly evident in the figures above. Faulkner's South, it's worth emphasizing, is the Confederate South, concentrated in the Eastern section where the major battles of the Civil War were fought. Faulkner's use of fictional names for key locations presents the first example of a common feature of modern regionalist texts. To reveal the degree to which these fictional names focalize location references in a corpus of this type, we have added Jefferson and Yoknapatawpha to our search for the second set of visualizations, bringing Mississippi into proper focus. The relative absence of New York and New England in Faulkner's corpus is worth noting as a testimony to the degree to which these regions had lost much of their cultural authority during the 
interwar years. Boston came to be seen as hopelessly parochial and "genteel," and New York, while still the capital of the American publishing industry, was perceived as more concerned with commerce than culture. Cultural authority had correspondingly shifted from commercial magazines such as the Atlantic and Harper's to little magazines, frequently based in Europe and, increasingly, university-based journals such as the Kenyon Review.
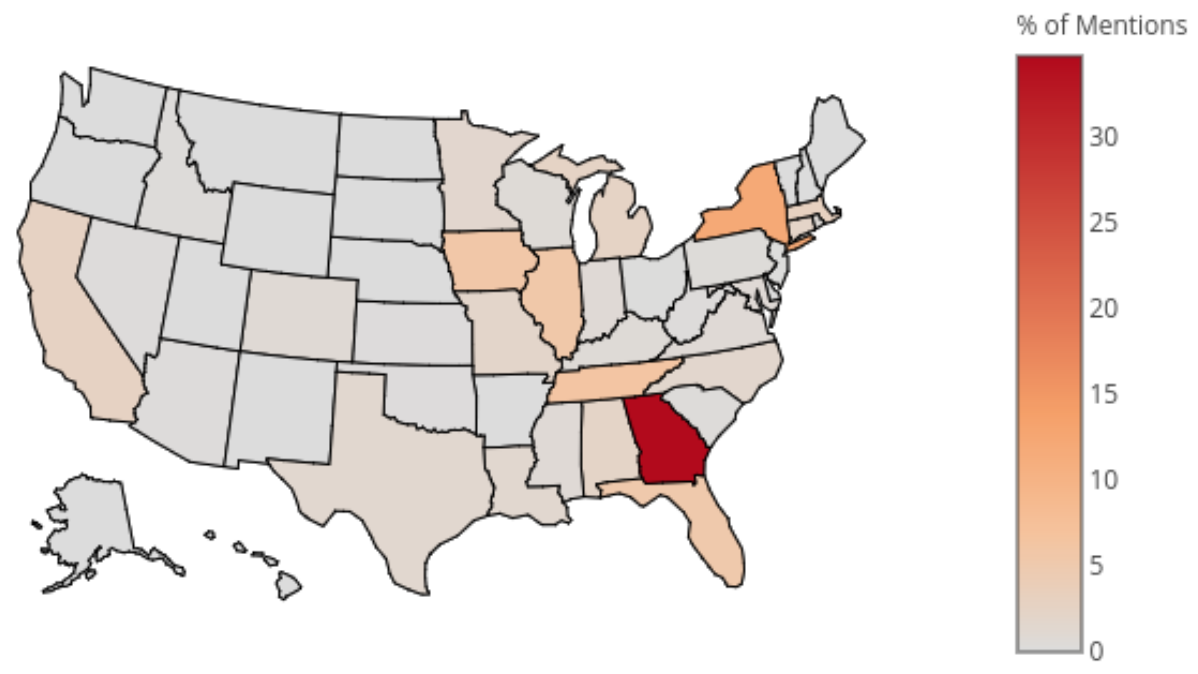

Figure 5. Total Mentions by State, Flannery O'Connor (1925-1964).

Attends Iowa Writers' Workshop, 1946-47. ${ }^{10}$

Flannery O'Connor's career marks the transition from Faulkner's interwar South, and its regional identity based in its underdevelopment by the industrial North, to an emergent regionalism based in the rise of creative writing programs, initially in the Midwest and West. If O'Connor wrote almost exclusively about her native South, she honed her style at the Iowa Writers' Workshop under Andrew Lytle, a Southern 
Agrarian on loan from Vanderbilt. The alliance between the New Critics based at Vanderbilt and Kenyon College and the faculty at the Iowa Writers' Workshop was exceptionally close during this formative period, and O'Connor's institutional and regional straddling is representative of this proximity in the immediate postwar era. Robert Penn Warren and Robert Lowell were both visiting professors in the English Department in these early years, and Austin Warren and René Wellek wrote Theory of Literature at Iowa while Paul Engle, the proud Midwesterner who directed O'Connor's thesis, was building the Workshop from an obscure experiment into a worldwide phenomenon. Engle's extensive network helped stitch the New Critical bastions of Vanderbilt and Kenyon to Washington, DC, New York City, and, by way of those metropoles and their powerful cultural bureaucracies and deep-pocketed foundations, to the world.

As Stephen Wilbers emphasizes, the Iowa Writers' Workshop itself developed out of regionalist sensibilities, but Midwestern regionalism would come to adopt a more accommodating attitude toward the surrounding world than the Southern Regionalism championed by the New Critics. ${ }^{11}$ Mark McGurl affirms that "Midwestern regionalism, as exemplified in Engle, looked outward and sought prestige through expansion [while] the Southern regionalists insisted that the regionalist project must turn inward and achieve literary excellence through exclusion." "12 The intersection between these two regionalist sensibilities, one insular and exclusionary and the other open and inclusive, laid the groundwork for the squatter regionalism that would characterize the Program Era.

It is important to situate squatter regionalism in the larger context of the GI Bill and the postwar boom in higher education in the United States. Louis Menand notes that between 1945 and 1975, "the number of American undergraduates increased by almost 500 percent and the number of graduate students by nearly 900 percent."13 Before WWII, the experience of "going away to college" was restricted to a relatively narrow band of (mostly male) cultural and economic elites, and it was certainly not the best option for a young person with literary aspirations. English departments were primarily philological in method, focused on British as opposed to American literature (which was rarely acknowledged as such); young Americans who wanted to be writers looked for apprenticeship in Europe, not higher education in the United States.

According to historian James Gregory, "World War II set off the greatest sequence of human migration in American History." 14 After WWII, demographically diverse 
access to postsecondary education expanded exponentially, making "going away to school" a national rite of passage for the American middle class, and graduates would frequently become as affectively attached to their college towns as their hometowns. Many of these college towns were in the Midwest, where massive (mostly public) multiversities began to draw students from the coasts, reversing the outward flow associated with classic regionalism. Indeed, mobility as such increased in the postwar era, so that Americans were less likely to have grown up in a single place for their entire childhood and also less likely to remain in a single place for their entire adulthood. In this more mobile environment, the college experience for many Americans supplemented or even replaced childhood as a period and place of sentimental attachment, generating the affective conditions of possibility for the creation and circulation of squatter regionalism.

\section{Squatter Regionalism}

"Squatter regionalism" designates those authors who write about the region in which they studied or taught creative writing, as opposed to the region in which they grew up. As initial examples, we offer a collection of authors associated with the Iowa Writers' Workshop who, though not Iowans, came to adopt and embrace Iowa and the Midwest as focal points for their writing. We will use our visualizations to confirm the degree to which a selection of these authors mention Iowa specifically or the Midwest generally in their fiction.

Our first example of squatter regionalism is Marilynne Robinson, recently retired as the F. Wendell Miller Professor of English and Creative Writing at the University of Iowa. Robinson was born in Sandpoint, Idaho, where her first novel, Housekeeping, takes place. After arriving in Iowa in her early forties, she became fascinated with the region and astonished by the relative absence of literary fiction representing it. She decided to write some herself, eventually publishing a series of celebrated novels with the fictional Midwestern town of Gilead, Iowa as their geographic and cultural focus. As with Faulkner, our second pair of visualizations include "Gilead" in the search terms. 

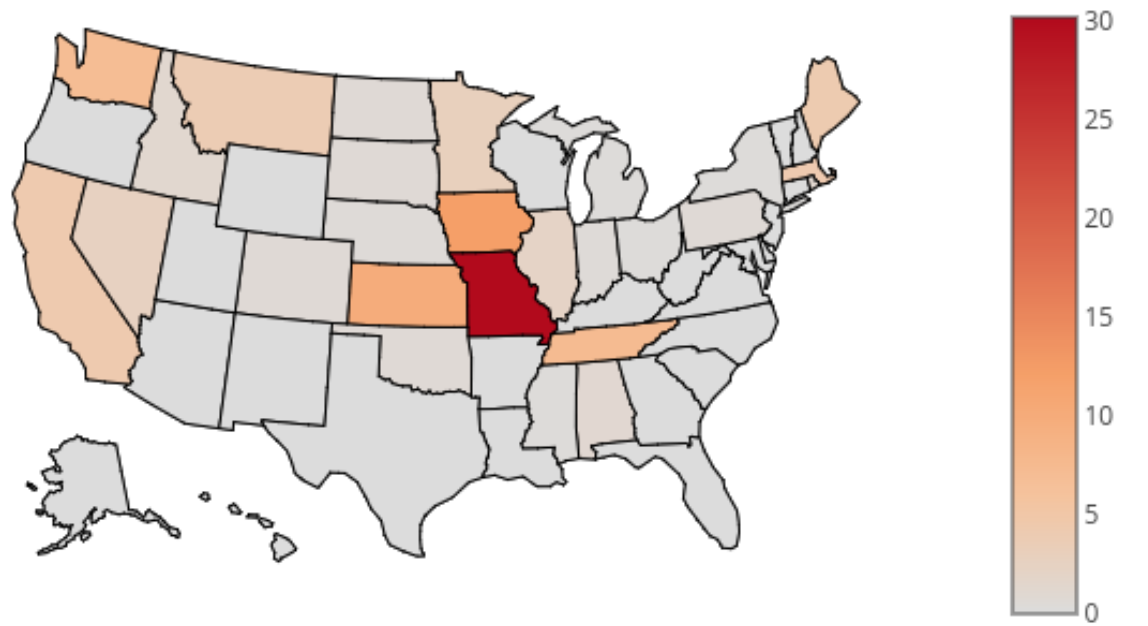


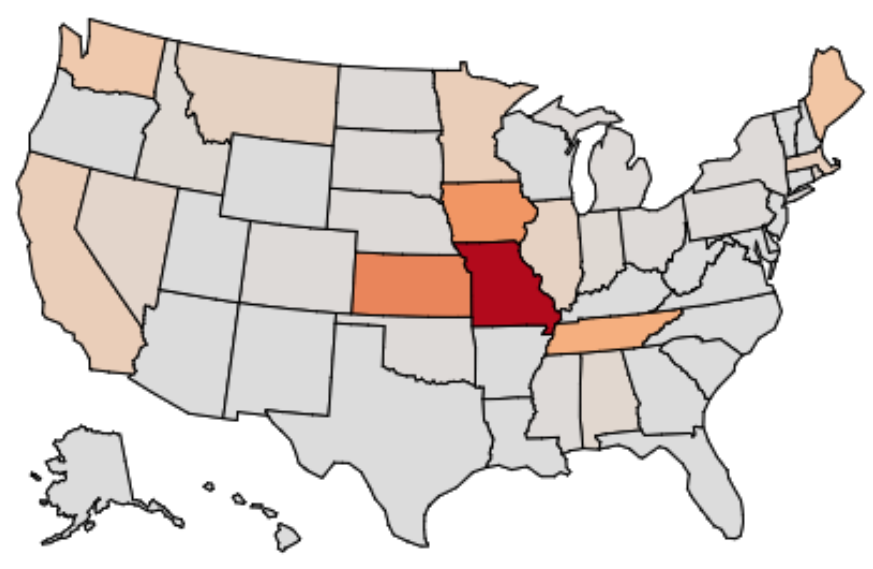

$\%$ of Mentions

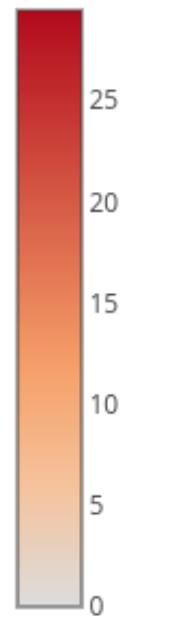

Figure 6. Average, Total Mentions by State, Marilynne Robinson Born in Idaho. Professor of English, Iowa Writers' Workshop $(1991-2016)^{15}$ 

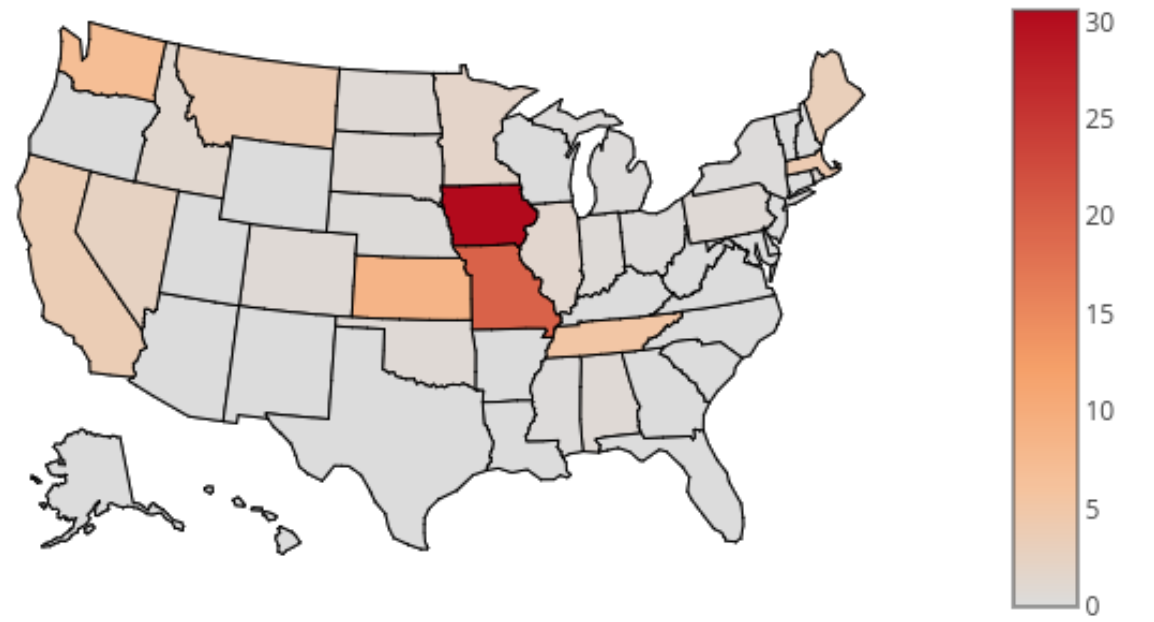

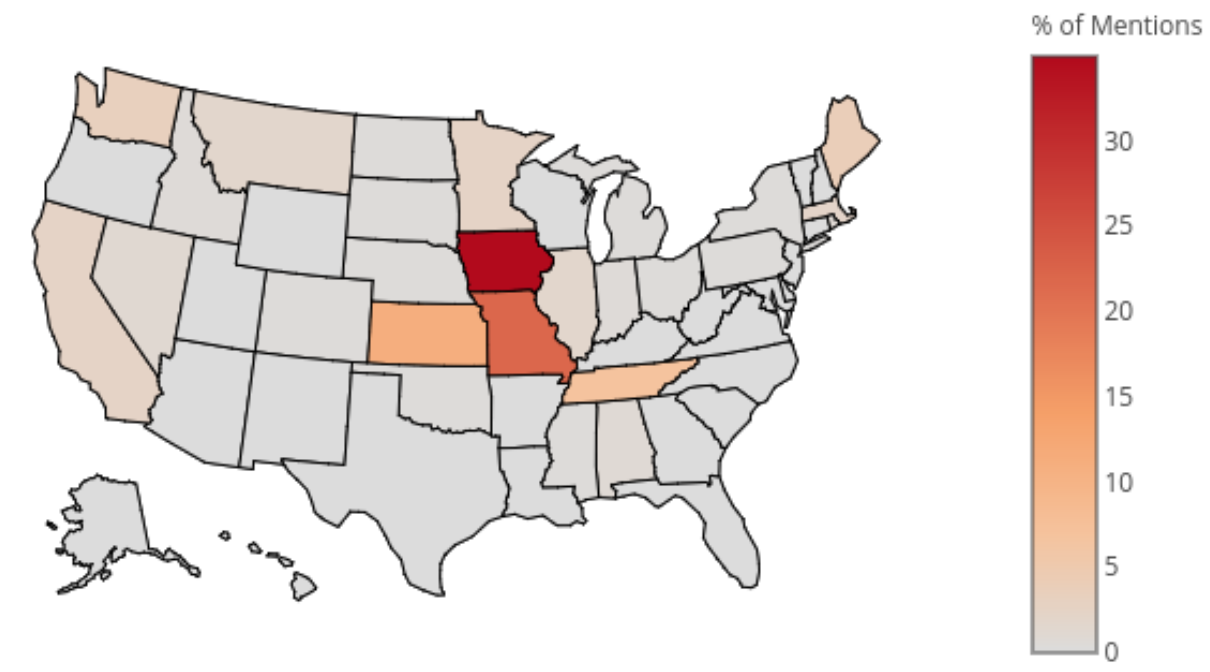

Figure 7. Average, Total Mentions by State, Marilynne Robinson Born in Idaho. Professor of English, Iowa Writers' Workshop (1991-2016) (Gilead Included)

The illustrations above map Robinson's version of the Midwest, which shades over from Iowa into Missouri and Kansas, where episodes in her saga take place. Insofar as Robinson expressly seeks to do for Iowa what Faulkner did for Mississippi, it is worth noting that Missouri and Kansas are border states where the racial conflicts of the South came up against the predominantly white culture of the Midwest. In a sense, Robinson uses Faulkner's South as a model for a culturally distinct region and imports it into a state whose regional identity has traditionally been vague and weak. 


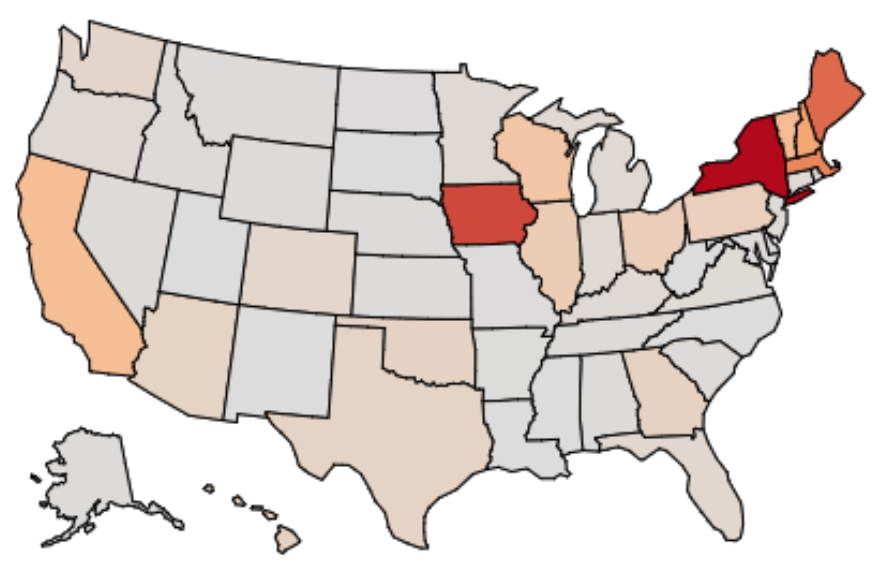

$\%$ of Mentions

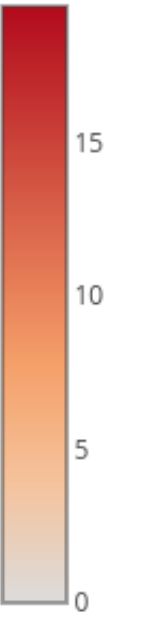



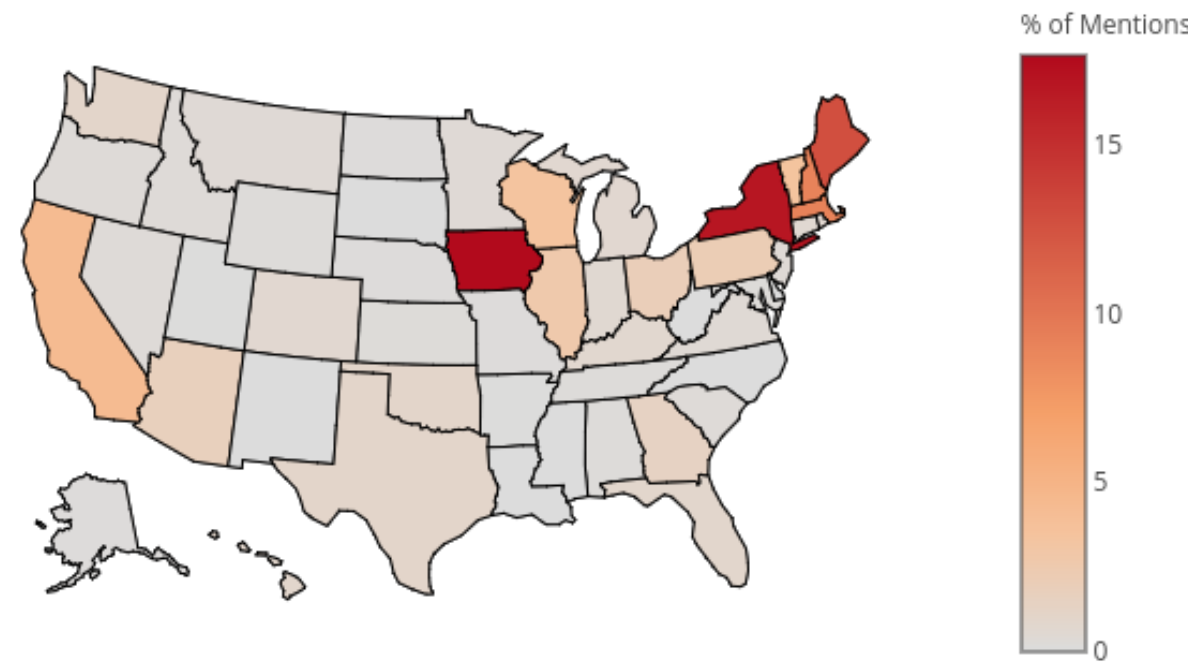

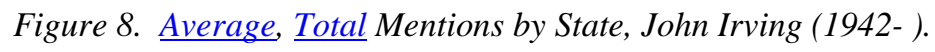

Born and raised in New Hampshire. MFA, Iowa Writer's Workshop (1967).

Taught at Iowa Writer's Workshop (1972-1975). ${ }^{16}$

We now turn to John Irving who, in an increasingly common creative writing career arc, has been both a student and a teacher at the Iowa Writers' Workshop. Irving was born in Exeter, New Hampshire, and much of his fiction takes place in New England. His work offers the first instance where our dual methods present notably different results, though both maps still indicate that Iowa, like New England, features prominently in his work. Indeed, many of his protagonists, like him, travel back and forth between the two locations. In our first map, which averages the proportions of location references by book, Iowa averages $14.5 \%$ of state mentions, second behind New York at $19.4 \%$. In the second map, which totals location references across the author's oeuvre total numbers, Iowa sits as the top spot with $17.6 \%$ of mentions, 
rising above New York, which has $16.8 \%$ of total references. We believe this variation is due to the density of location references in many of Irving's works. In our fiction corpus, Irving's novels often rank among the most location rich. Hotel New Hampshire has nearly 700 location hits, while Until I Find You and The Water-Method Man both have roughly 400 hits. In his most location-heavy works, Iowa references are dominant. For instance, in The Hotel New Hampshire, Iowa's references are more than triple New York's. And Iowa references are double New York's in The Water-Method Man, a work which features a former University of Iowa graduate student as its protagonist. Collectively, such location-heavy, Iowaheavy works tip the balance when Irving's averaged representation numbers are compared to state representation in the total corpus.

Given Irving's sustained popularity across the late twentieth century, it is not a stretch to say that many readers, both in the United States and around the globe, first come to know Iowa as a state and the Midwest as a region from this writer, New England born and bred. As with Robinson, we find a writer who bolsters the image of the Midwest by mapping it in terms of a more well-known and well-established regional identity. Its agricultural identity gets supplemented by an institutional itinerary associated with the postwar boom, where college towns loom large.

Last, we consider W.P. Kinsella, a writer closely associated with Iowa, though he was born and raised in rural Alberta and didn't arrive in Iowa City to attend the Writers' Workshop until he was well into adulthood. Though he only spent a few years in the state, he dedicated a series of magical realist novels and short story collections to it. The Iowa Baseball Confederacy (1986) directly draws from (indeed parodies) Wilbers's history of the Writers' Workshop (Wilbers was working on his history as a doctoral dissertation when Kinsella matriculated). Shoeless Joe (1982) was adapted into the blockbuster film Field of Dreams (1989), which put Iowa on the cultural map, catapulting the little-known state to global prominence and enhancing its appeal as a tourist destination.

Kinsella appropriated not only a region but a culture, as many of his characters are indigenous inhabitants of Iowa (itself an indigenous term, as are many places in the state), upon whom he bases the state's folklore and cultural identity. While his decision to write fiction based in Iowa was uncontroversial, his representation of native voices has received frequent criticism as cultural appropriation. In a sense, indigenous voices do for Kinsella what race does for Robinson: they create a groundwork of cultural conflict out of which regional identity emerges. 


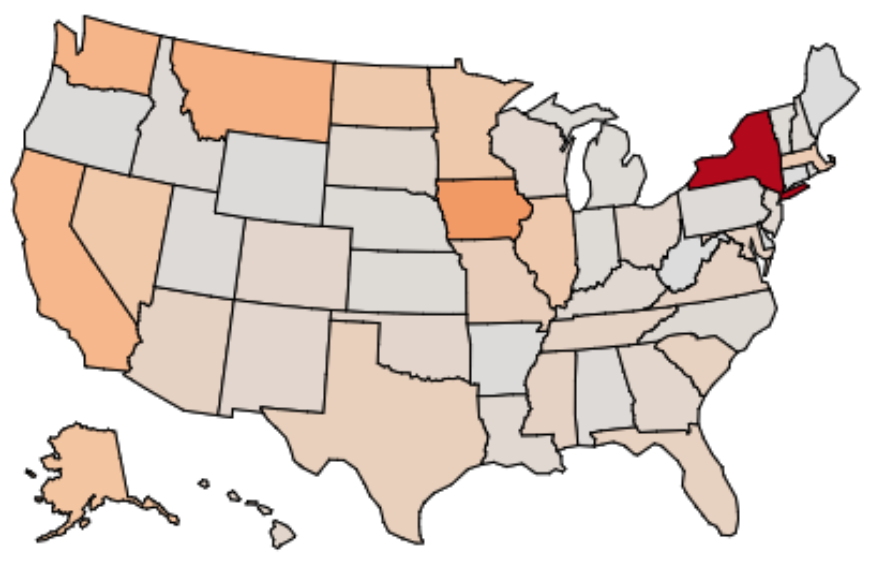

$\%$ of Mentions

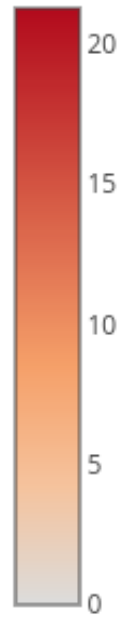




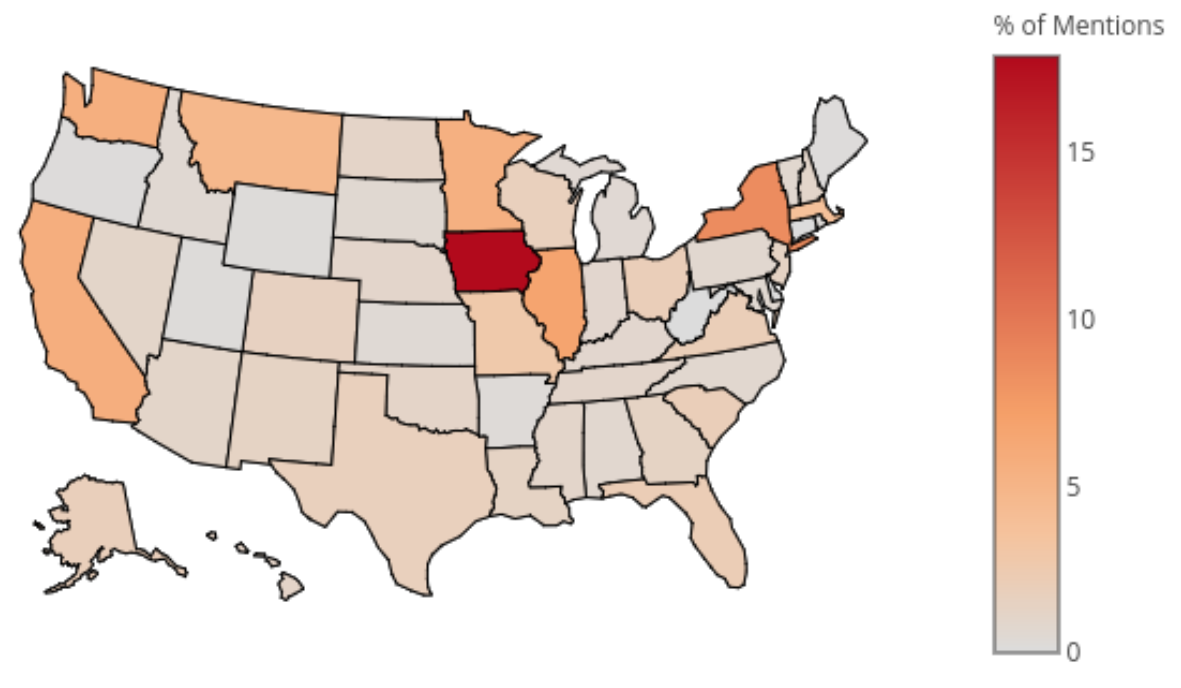

Figure 9. Average, Total Mentions by State, W. P. Kinsella (1935-2016).

\% of Total Mentions from Full HTRC Corpus Collection. ${ }^{17}$

With Kinsella, we again see a divergence between averaged and totaled maps. In the averaged visualization, New York maintains an edge at roughly $21 \%$, though Iowa also has a notable degree of representation at 9\%. These high New York averages come from a handful of Kinsella works that mention New York locations much more than other state locations (i.e. Born Indian, Dance Me Outside) but, compared to Kinsella's Iowa writing, have a lower number of place name mentions. Kinsella's investment in Iowa becomes truly apparent when we look at the percentages across his entire corpus. Here we see how Iowa becomes the center of Kinsella's geographic imagination, even though he only lived there for a brief period. ${ }^{18}$ 


\section{Corpus Comparison and Demographic Data}

Wilkens found in his study of nineteenth-century texts that geographic reference counts are often tied closely to state population. Therefore, he suggests that a fruitful way to measure and explore the representation of states in a given corpus would be to "compare the fraction of all named-location occurrences that fall with a region to that region's fraction of the overall population." recent census data on what percentage of the U.S. population lives in Iowa with the average percentage of state references to Iowa in our Workshop corpus to see if, and how much, the percentages differed. Current 2017 estimates of state and national population by the U.S. Census Bureau put Iowa's population at approximately $3,145,711$ and the national population at approximately $325,719,178$. This means Iowa currently represents about $.97 \%$ of the U.S. population.

This tracks well with TxtGeo's numbers for Iowa. As the image below indicates, when the TxtGeo tool is asked to produce a state-based breakdown of place references found in books published between 1930 and 2015 and categorized under the Library of Congress Classification "Language and Literature," TxtGeo finds that Iowa comprises $1.058 \%$ of references, about 1.10 times the population figure. By contrast, in our corpus the average Iowa Writers' Workshop text references Iowa 3.2 times, more than three times as often. If we count just the total mentions for each state, the number increases to approximately 4.2 percent, four times the population figure. 


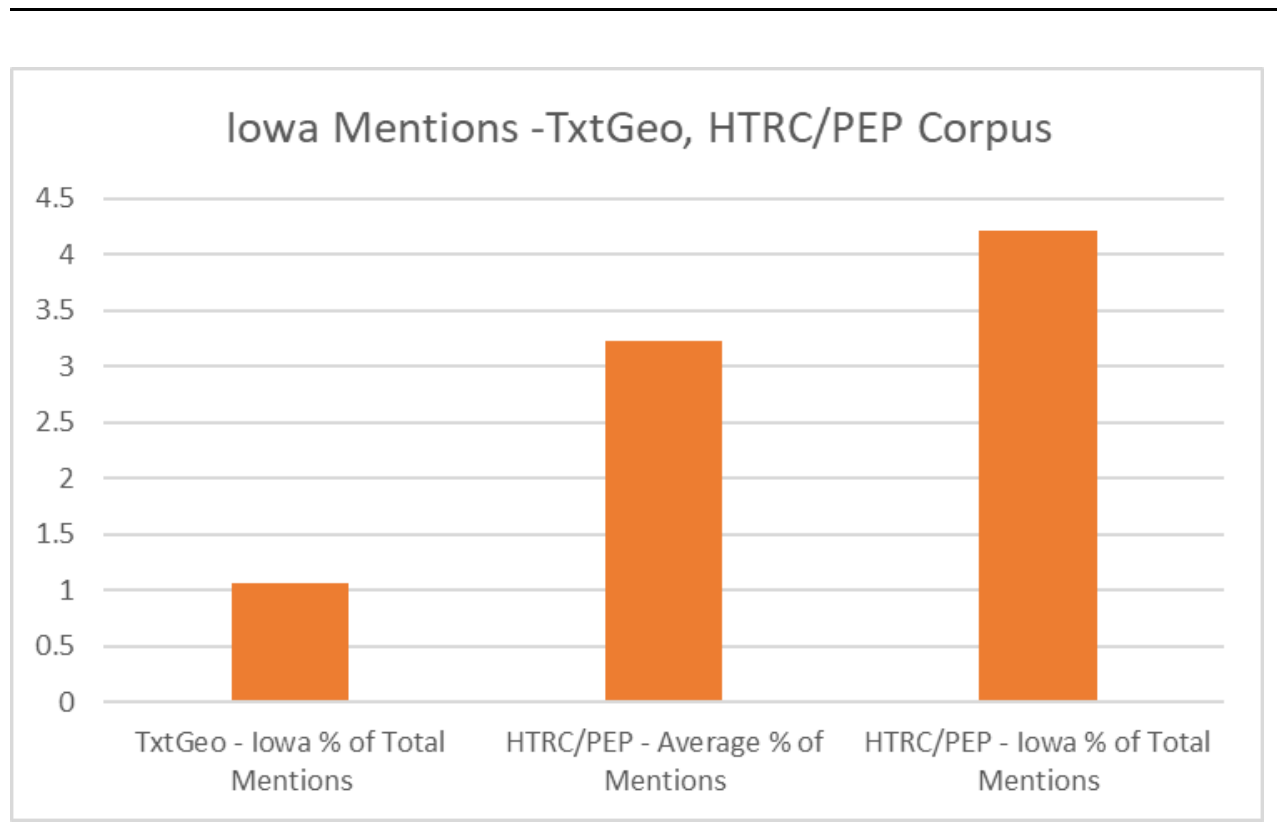

Figure 10. Total Mention by State, TxtGeo Corpus,

Average, Total Mention by State HTRC/PEP Fiction Corpus

While New York and California represent a large percentage of the location references found in our corpus, looking at the averaged and total mention percentages reveals some significant details. First, after the prominence of New York and California (which account for approximately 30\% of total place references), there is a rapid drop off in how often states are mentioned. Illinois and Massachusetts average approximately 5\%, about half of California (with $10 \%$ of total mentions) and a quarter of New York (with 20\%). More significant for our purposes is Iowa's location in the rankings of frequently-represented states; it ranks $6^{\text {th }}$ in terms of average percentage of total mentions and $5^{\text {th }}$ in total mentions, much higher than its ranking of $27^{\text {th }}$ in the TxtGeo corpus.

We now turn to geographic trends in IWW graduation cohorts. Since the founding of the PEP, the team has worked to collect publicly available demographic data on Workshop students and faculty. Most significantly for this project, we collected selfdeclared hometowns from graduation ceremony programs held in the University Archives. When rankings of the top states listed by IWW graduates are first examined, the results initially suggest a surprisingly high representation of Iowa. 


\begin{tabular}{|l|l|l|}
\hline State & Graduates & $\%$ of Total \\
\hline IA & 822 & 29.89091 \\
\hline NY & 266 & 9.672727 \\
\hline CA & 236 & 8.581818 \\
\hline IL & 148 & 5.381818 \\
\hline PA & 109 & 3.963636 \\
\hline MA & 106 & 3.854545 \\
\hline OH & 76 & 2.763636 \\
\hline NJ & 64 & 2.327273 \\
\hline TX & 58 & 2.109091 \\
\hline CT & 51 & 1.854545 \\
\hline
\end{tabular}

Figure 11. Top 10 States Listed as Hometown, IWW Graduation Records

We hypothesize that this prominence is caused by the considerable number of Workshop graduates who claim Iowa City as their hometown, even though many if not most of them were not born or raised there. Unlike undergraduates, graduate students frequently list their current location as their hometown, rather than the place in which they were raised. Furthermore, many of the early IWW cohorts were older than the average graduate student; they were returning to school after stints in the service or disappointments with their initial careers. Many were married with children and happy to call Iowa "home." We can easily compare graduate records with external biographical information to find cases of hometown false positives attributed to Iowa City or Coralville (a city adjacent to Iowa City). For example, both Jane Smiley, who was born in Los Angeles and grew up in Missouri, and T.C. Boyle, who was born and raised in New York, listed Iowa City as their hometown. This very fact supports our hypothesis insofar as it indicates the frequency with which writers who come to Iowa City adopt it as their "home." When we remove 
Iowa City and Coralville from our list, we get a much more realistic picture of geographic representation in IWW graduate cohorts, shown below listing the top 10 states (figure 12).

\begin{tabular}{|l|l|l|}
\hline State & Graduates & \% of Total \\
\hline NY & 266 & 12.79461 \\
\hline CA & 236 & 11.35161 \\
\hline IA & 151 & 7.263107 \\
\hline IL & 148 & 7.118807 \\
\hline PA & 109 & 5.242905 \\
\hline MA & 106 & 5.098605 \\
\hline OH & 76 & 3.655604 \\
\hline NJ & 64 & 3.078403 \\
\hline TX & 58 & 2.789803 \\
\hline CT & 51 & 2.453102 \\
\hline
\end{tabular}

Figure 12. Top 10 States Listed as Hometown, IWW Graduation Records

(Iowa City and Coralville Removed)

Through these figures, we get a clearer picture of where Workshop students come from. Iowa remains highly ranked, though some of this prominence could still be tied to students living in communities near Iowa City and listing their current locations as hometowns. It is, of course, worth noting the prominence of New York and California as 24\% of graduates, nearly one in four, list either New York or California as their home state. Over one in eight graduates list New York as their home. This clearly demonstrates that there is an established pattern, tracing back to the origins of the Workshop, of coastal residents migrating to Iowa to acquire an 
MFA. A considerable number remain or return. Again, it is worth noting how dramatically this reverses demographic trends extending back to the era of classic regionalism, when American writers left the rural heartlands for the urban coasts and beyond.

By combining our demographic information about hometowns with our textual metrics, we are able to confirm our hypothesis regarding "squatter regionalism" and the Program Era, at least as it concerns the Iowa Writers' Workshop.

\begin{tabular}{|l|l|l|}
\hline Author Name & Work Name & $\begin{array}{l}\text { IA of Total } \\
\text { Mentions }\end{array}$ \\
\hline Cassill, R. V. & The happy marriage, and other stories & 51.35135135 \\
\hline McCracken, Elizabeth & Niagara Falls all over again & 48.553054466 \\
\hline Irving, John & The water-method man & 46.678526 \\
\hline Irving, John & 3 by Irving & 40.94853409 \\
\hline Cassill, R. V. & Three stories & 40 \\
\hline Stuckey-French, Elizabeth & $\begin{array}{l}\text { The first paper girl in Red Oak, Iowa; } \\
\text { and other stories }\end{array}$ & 38.11881188 \\
\hline Shields, David & Heroes & 33.83806071 \\
\hline Smiley, Jane & At paradise gate & 31.94444444 \\
\hline Kinsella, W. P. & Shoeless Joe & 31.58414213 \\
\hline Tiempo, Edilberto K. & $\begin{array}{l}\text { Finalities: a novelette and five short } \\
\text { stories }\end{array}$ & 28.88888889 \\
\hline Irving, John & The Hotel New Hampshire & 28.37671402 \\
\hline Grumbach, Doris & The spoil of the flowers & 28.12656956 \\
\hline Yates, Richard & Young hearts crying & 28.10110326 \\
\hline Smiley, Jane & A thousand acres & 27.7027027 \\
\hline Wittinger, Ellen & Lombardo's law & 25.66666667 \\
\hline Stefaniak, Mary Helen & Self storage and other stories & 24.3902439 \\
\hline Schramm, Wilbur Lang & Windwagon Smith and other yarns & 22.64150943 \\
\hline Godwin, Gail & Evenings at five & 22.22222222 \\
\hline
\end{tabular}




\begin{tabular}{|l|l|l|} 
Irving, John & The 158-pound marriage & 20.125 \\
\hline Cheever, John & Oh, what a paradise it seems & 20 \\
\hline Haldeman, Joe W. & Camouflage & 19.62616822 \\
\hline Cassill, R. V. & Collected Stories & 19.3043674 \\
\hline Louie, David Wong & The barbarians are coming: a novel & 18.57923497 \\
\hline Grumbach, Doris & The magician's girl & 17.6744186 \\
\hline Kinsella, W. P. & $\begin{array}{l}\text { The further adventures of Slugger } \\
\text { McBatt: baseball stories }\end{array}$ & 16.93693694 \\
\hline
\end{tabular}

Figure 13. Top 25 Works, Iowa \% of Total Location Mentions

The chart above starkly illustrates the degree to which most of the Workshop writers who focus on Iowa in their work are not from Iowa originally. It lists the 25 novels or short story collections in which Iowa has the highest percentage of location references. Other than R.V. Cassill (who ultimately left Iowa), none of these authors are Iowans. Rather than (or in addition to) writing about where they're from, they've decided to write about where they've gone, where they ended up, permanently or temporarily, in pursuit of their careers in creative writing. Their focus has been sustained enough, we think, to transform the geographic imagination of the postwar era. Prior to the Program Era, Iowa was next to invisible in American literature, and the Midwest featured mostly as a place people left. Now, Iowa is a central node in a world literary network, and the Midwest has emerged as a location of extensive thematic and cultural interest.

From our graduation data, we can see how the Workshop draws students from across the United States. Our analysis of Workshop fiction shows that while our authors often gravitate towards writing about the coasts, their location references to Iowa make up a significantly higher percentage of total location references than comparable corpora. When we look at the works that reference Iowa most frequently, we see that an overwhelming majority of those works were authored by Iowa visitors or transplants. Furthermore, Iowa has become, both nationally and internationally, a required stop on the professional itinerary of any creative writer of any reputational stature, enhancing its prominence in the regional imaginary of postwar fiction. 
The increasing precariousness of the academic job market has only enhanced this prominence. In 2011, Poets \& Writers conducted a survey of 640 MFA program applicants, assessing which MFA programs the potential students applied to. Of the 640 survey participants, $404(63 \%)$ applied to the Workshop. The second highest ranked program in the survey (University of Michigan) saw only 221 applications from survey respondents. ${ }^{20}$ According to a 2015 New York Times article on MFA applications and employment, the Workshop received 1380 applications for 50 open spots that year. The piece goes on to note that about 20,000 applications would be sent to MFA programs in 2015, and that 3,000 to 4,000 MFAs would graduate. For those thousands of graduates, 112 tenure-track creative writing positions were available. ${ }^{21}$ In short, if a common creative writing maxim may be "write what you know," socioeconomic and reputational forces dictate what places the most promising writers are likely to get to "know." Add to this the increasing prominence of memoir and autofiction in the contemporary literary field and the expansion of writing programs at the University of Iowa (which currently includes the International Writing Program, the Nonfiction Writing Program, the Translation Program, and the Center for the Book, among others), it should not be surprising that Iowa appears with increasing frequency in literary fiction and nonfiction.

We speculate that similar patterns in attendance and representation may be seen in work produced in other prominent programs, such as Stanford for the West, but that's material for another study, a study to be drawn from corpora yet to be assembled. We hope that our initial exploration of the Iowa Writers' Workshop and our collaboration with HathiTrust's ACS program offer a model that other institutions could follow, should they be interested in exploring the potential significance of their own MFA programs on literary geographic representation. Additionally, it is our hope our collaboration with HathiTrust suggests a path forward for scholars of contemporary literature attracted to computational methodologies but stymied by the access difficulties of working with texts in copyright.

It is for these reasons that we seek to analyze, with our technology and our computational methods, geographical representation in our corpus in a way that is as transparent and technically legible as possible. We deliberately strive to develop methods that could invite discussion from both technically sophisticated and traditionally trained literary scholars, methods that avoid, whenever possible, a perception that our visualizations emerge from a computational black box. We invite and welcome suggestions on methods and techniques, ways to rethink or improve 
our tool both computationally and in its statistical grounding. Particularly, we invite any suggestions regarding the disambiguation process, perhaps the thorniest component of any location-tracking technology. Our aim is to integrate what suggestions we can while, ideally, maintaining intelligibility.

Simultaneously, we acknowledge the limitations, in terms of both corpus and technology, in this study. Our tool leans towards urban rather than rural locations. Our corpus, while the largest of its kind assembled, is not representative of Workshop writing as a whole. Indeed, given that none of the IWW theses have been (or are likely to be) digitized, the task of creating a truly representative corpus is perhaps impossible and certainly unlikely.

Nevertheless, we believe that our analysis offers the most comprehensive mapping to date of the geographic imaginary of the Iowa Writers' Workshop and could indicate larger geographic trends in postwar fiction. Both institutionally and aesthetically, there remains much to be examined, mapped, and better understood about the Program Era. We offer this exploration as one model of how future scholarship might chart a course into this literary territory.

\section{References}

${ }^{1}$ Tom Lutz, Cosmopolitan Vistas: American Regionalism and Literary Value (Ithaca: Cornell University Press, 2004) 191-92.

${ }^{2}$ In a few cases, some variations on these criteria were employed to help produce more accurate results. Our tool does not count "Washington" as referring to the state of Washington. It excludes references to geographic features that are also state names. City names that are common first names (Charlotte, Norman) are omitted. City names that are geographic features (Mesa, Butte) are omitted. Extremely common city names shared across states (Springfield, Columbus) are omitted. When a city in a state is omitted, the next most populous city in that state is included instead. The tool also tracks references to well-known city nicknames such as "Windy City," "Sin City," or "Big Apple."

${ }^{3}$ See Matthew Wilkens, "The Geographic Imagination of Civil War-Era American Fiction," American Literary History 25:4 (Winter 2013): 804.

${ }^{4}$ See Michael Gavin and Eric Gidal's "Scotland's Poetics of Spcace: An Experiment in Geospatial Semantics" in Cultural Analytics at https://culturalanalytics.org/article/11072-scotland-s-poetics-of-space-an-experiment-ingeospatial-semantics . 
${ }^{5}$ By gathering archives of place names from external sources, relying on unambiguous contextual place references, and weighing the overall likelihood of a place reference, Crane and Smith map the possible locations with which a given term might be associated on a grid. They then assign the ambiguous term to the location to which it most likely refers based on a combination score of its similarity to the last four location references in the text and the location reference that most closely aligns to the centroid of their weighted reference score map.

${ }^{6}$ Such false positives are excluded from any state-related count as the disambiguation tool collects context. For instance, the tool simultaneously filters out and keeps count of any "Mr. Henderson" "Mrs. Henderson" "Sgt. Henderson" etc. while counting for potential references to Henderson, Nevada. The tool also employs a list of over 8,000 first names collected by Stanford's Natural Language Toolkit to track for any cases of a first name + city name combination to exclude these false positives from city counts.

${ }^{7}$ Works Included: A Spoil of Office, The Captain of the Grey Horse Troop, Cavanagh, Forest Ranger, A Daughter of the Middle Border, The Eagle's Heart, A Little Norsk, Main-Travelled Roads (Collection), The Moccasin Ranch, Money Magic, A Pioneer Mother, Prairie Folks (Collection), Rose of Dutchers Coolly, The Shadow World, A Son of the Middle Border, The Spirit of Sweetwater, The Light of the Star, They of the High Trails, The Trail of the Gold Seekers, The Tyranny of the Dark, Victor Ollnee's Discipline, Wayside Courtships (Collection).

${ }^{8}$ Works Included: A White Heron and Other Stories (Collection), An Arrow in a Sunbeam and Other Tales (Collection), Betty Leicester's Christmas, Betty Leicester: A Story for Girls, A Country Doctor and Selected Stories (Collection), The Country of Pointed Firs, Deephaven and Selected Stories and Sketches, The Life of Nancy (Collection), A Marsh Island, Old Friends and New (Collection), The Queen's Twin and Other Stories (Collection), Strangers and Wayfarers (Collection), The Tory Lover.

${ }^{9}$ Works Included: A Fable, Soldier's Pay, The Hamlet, The Sound and the Fury, The Town, Absalom Absalom!, As I Lay Dying, Intruder in the Dust, Mosquitoes, Requiem for a Nun, Sanctuary, The Mansion, The Unvanquished, The Wild Palms.

${ }^{10}$ Works Included: Collected Works. Because this corpus consists of a complete, single collection, there is only one metric for percentage of total mentions.

${ }^{11}$ Stephen Wilbers, The Iowa Writers' Workshop: Origins, Emergence, Growth (Iowa City: University of Iowa Press, 1980) 3-18.

${ }^{12}$ Mark McGurl, The Program Era: Postwar Fiction and the Rise of Creative Writing (Cambridge: Harvard University Press, 2009), 151.

${ }^{13}$ Louis Menand, The Marketplace of Ideas: Reform and Resistance in the American University (New York: W.W. Norton, 2010), 64.

${ }^{14}$ James N. Gregory, "Internal Migration: Twentieth Century and Beyond," in Oxford Encyclopedia of American Social History (New York: Oxford University Press, 2012), 542.

${ }^{15}$ Works Included: Gilead, Home, Housekeeping, Lila. Because only one work by Robinson was available from the HTRC corpus, we have used a separate corpus of Robinson's works for this map.

${ }^{16}$ Works Included: A Prayer for Owen Meany, A Son of the Circle, Three by John Irving (Collection), A Widow for One Year, Trying to Save Piggy Sneed (Collection), Until I Find You, The 158-Pound Marriage, The Cider House Rules, The Fourth Hand, The Hotel New Hampshire, Setting Free the Bears, The Water-Method Man, The World According to Garp. 
${ }^{17}$ Works Included: The Alligator Report (Collection), Born Indian (Collection), Box Socials, Brother Franks Gospel Hour (Collection), Dance Me Outside, The Further Adventures of Slugger McBatt (Collection), Red Wolf, Red Wolf (Collection), Scars (Collection), Shoeless Joe.

${ }^{18}$ At this point, our tool doesn't track international location references, other than for disambiguation purposes, so we cannot include Kinsella's Canadian locations in our visualizations. Our goal has been to determine the representation of Iowa compared to other U.S. states. In addition to tracking U.S. territories, a future version of the PEP tracking tool will include international representation and will hopefully offer new insights into the increasingly global scope of the IWW particularly and creative writing programs more generally.

${ }^{19}$ Wilkens, “Geographic Imagination,” 810.

${ }^{20}$ Full survey results can be found at "2012 MFA Rankings: Top Fifty," Poets\&Writers.org, September 1, 2011.

${ }^{21}$ See Cecilia Capuzzi Simon, "Why Writers Love to Hate the M.F.A.," 